\title{
Influence of surfactant concentration on nanohydroxyapatite growth
}

\author{
D GOPI $^{1,2, *}$, J INDIRA ${ }^{1}$, S NITHIYA ${ }^{1}$, L KAVITHA ${ }^{2,3}$, U KAMACHI MUDALI ${ }^{4}$ \\ and K KANIMOZHI ${ }^{1}$ \\ ${ }^{1}$ Department of Chemistry, Periyar University, Salem 636 011, India \\ ${ }^{2}$ Centre for Nanoscience and Nanotechnology, Periyar University, Salem 636 011, India \\ ${ }^{3}$ Department of Physics, Periyar University, Salem 636 011, India \\ ${ }^{4}$ Corrosion Science and Technology Division, Indira Gandhi Centre for Atomic Research, Kalpakkam 603 012, India
}

MS received 17 January 2012; revised 23 July 2012

\begin{abstract}
Nanohydroxyapatite particles with different morphologies were synthesized through a microwave coupled hydrothermal method using CTAB as a template. A successful synthesis of nanosized HAP spheres, rods and fibres is achieved through this method by controlling the concentration of the surfactant. The concentration of the surfactant was tuned in such a way that the desired HAP nanostructures were obtained. The resultant powders were sintered at $900{ }^{\circ} \mathrm{C}$ in order to obtain phase pure HAP particles. The results obtained by Fourier transform infrared spectroscopy (FT-IR), X-ray diffraction analysis (XRD), scanning electron microscopy (SEM) and transmission electron microscopy (TEM) techniques have substantiated the formation of nanosized HAP spheres and fibres.
\end{abstract}

Keywords. Biomedical applications; hydroxyapatite; microwave processing; calcination; X-ray methods.

\section{Introduction}

Hydroxyapatite $\left[\mathrm{Ca}_{10}\left(\mathrm{PO}_{4}\right)_{6}(\mathrm{OH})_{2}, \mathrm{HAp}\right]$, the prime constituent of bone and teeth has attracted a great deal of attention in biomedical applications owing to its close similarity in chemical composition with the mineral part of natural bone and teeth (Hench 1991; Rambo et al 2006; Kalita et al 2007). Recently, main interest is not only controlling the stoichiometry of synthetic HAp, but also to control the shape, size and agglomeration characteristics of their particles (Walsh and Mann 1996; Sarda et al 1999). It has been shown that many clinical applications of HAp mainly depend on shape, morphology and size of HAp particles (Suchanek and Yoshimura 1998). Hence, it is possible to enhance the biological performance of hydroxyapatite by controlling the morphology, particle size and distribution. Therefore, a number of processing routes have been developed for preparing hydroxyapatite powders, including sol-gel (Bezzi et al 2003; Anee Kuriakose et al 2004), hydrothermal (Hattori and Iwadate 1990; Remant Bahadur et al 2008), microemulsion (Murray et al 1995; Lim et al 1996) and mechanochemical (Kim et al 2000; Yeong B et al 2001) methods. Recently, we have reported the synthesis of nanohydroxyapatite particles by an ultrasonic coupled sol-gel method (Gopi et al 2008).

Eventhough these methods have been used to fabricate nanosized HAp, there are intensive interests to find gentle and rapid ways for the synthesis of pure hydroxyapatite nanoparticles. Mass production of high purity hydroxyapatite is reported via time-consuming and tedious processes

\footnotetext{
*Author for correspondence (dhanaraj_gopi@yahoo.com)
}

only (Lerner et al 1991). Microwave irradiation is an efficient method which solves this problem and provides rapid, facile and convenient synthesis procedures (Lerner et al 1991; Macipe et al 1998; Sarig and Kahana 2002; Liu et al 2005; Rameshbabu et al 2005). Hence, microwave heating has been employed instead of conventional heating to synthesize nanosized hydroxyapatite particles owing to its unique heating features and precipitation of nanosized HAp using microwave irradiation has also been reported (Arami et al 2009). Microwave irradiation can be successfully used for synthesizing various nanostructured materials due to its unique properties and is increasing the yield of precipitations (Jiang et al 2006; Yang et al 2007).

Although control over microstructure seems to be a big challenge with traditional methods, it is known that the controlled nucleation and crystal growth process mediated by macromolecular control would finally result in uniform and fine-shaped products. Traditional clinical applications of calcium phosphates have mainly focused on highly crystalline ceramics (Liu et al 2002). Therefore, it is important to synthesize HAp nanofibres for biomedical applications. Previous studies have shown that nanofibres affect the cellular behaviour by the way of promoting proliferation and differentiation of cells. This phenomenon occurs because, the cells attach and organize around the fibres with diameters smaller than that of cells and hence, can be utilized in the biomedical field (Laurencin et al 1999; Yeong K C B et al 2001). In this context, several macromolecules, such as stearic acid, monosaccharides and related molecules have been explored already with a desired control on the morphology. Hence, in order to control the size and morphology of HAp, we have chosen cetyl trimethyl ammonium bromide 
(CTAB) as a cationic surfactant, which was widely used to achieve control of the morphology in many aqueous synthetic methods.

Liu et al (2002) reported the synthesis of HAP nanofibres with diameter of 5-8 nm and length of 160-220 nm using the templates such as CTAB, polyethylene glycol (PEG) and cyclohexane. In a similar manner, Sun et al (2006) reported the synthesis of single crystal HAp nanorods with diameter, $8-15 \mathrm{~nm}$ and length, $25-30 \mathrm{~nm}$ by using the quaternary reverse microemulsion (TX-100+CTAB $/ n$-butanol+ $n$-exanol/cyclohexane/water) method. Another method like hydrothermal microemulsion was proposed by Kalita et al (2007) for the synthesis of nanohydroxyapatite rods using $\mathrm{CTAB}$ as the surfactant and $n$-pentanol as the cosurfactant. However, the foresaid researchers neither used CTAB alone as a template nor optimized its concentration on the size and morphology of the as-synthesized HAp during synthesis.

Arami et al (2009) reported the synthesis of hydroxyapatite nanostrips by using microwave heating method and $\mathrm{CTAB}$ as a template. But the effect of CTAB concentration on phase purity, crystallinity and morphology of the as-synthesized HAp using this microwave heating method was not investigated. On the other hand, Yan et al (2001) reported the synthesis of HAp nanorods using surfactants, CTAB and sodium dodecylsulphate (SDS), under hydrothermal conditions at $150{ }^{\circ} \mathrm{C}$. However, they failed to attempt the effect of surfactant concentration on morphology of the as-synthesized HAp. Salarian et al (2009) also reported the synthesis of hydroxyapatite nanorods by surfactant-assisted hydrothermal method. In their synthesis, CTAB acts as a soft template and PEG 400 acting as a co-template. They investigated mainly the effect of hydrothermal temperature alone on composition, size and morphology of as-synthesized HAp.

Motivated by the above, in this paper, we focus our attention to investigate the effect of various concentrations of CTAB as an only surfactant on the structural growth of nanohydroxyapatite using microwave irradiation method. Through our systematic investigation, it was found that fine adjustments in the surfactant concentrations under microwave irradiation method effectively modify the size as well as shape of nanohydroxyapatite particles. The influence of varying concentration of $\mathrm{CTAB}$ under microwave irradiation method on morphology and size of the nanohydroxyapatite particles is studied and presented.

\section{Experimental}

Analytical grade calcium nitrate $\left(\mathrm{Ca}\left(\mathrm{NO}_{3}\right)_{2} \cdot 4 \mathrm{H}_{2} \mathrm{O}\right.$, Merck, India) and dipotassium hydrogen phosphate $\left(\mathrm{K}_{2} \mathrm{HPO}_{4} \cdot 3 \mathrm{H}_{2} \mathrm{O}\right.$, Merck, India) were used as precursors for calcium and phosphate, respectively. Along with this, Analar grade ammonia (Merck, India) and CTAB (Merck, India) were also used in the synthesis of HAp.

The precursor solutions were prepared by dissolving $\mathrm{K}_{2} \mathrm{HPO}_{4} \cdot 3 \mathrm{H}_{2} \mathrm{O}(0.024 \mathrm{M})$ and $\mathrm{Ca}\left(\mathrm{NO}_{3}\right)_{2} \cdot 4 \mathrm{H}_{2} \mathrm{O}(0.04 \mathrm{M})$
(Merck, India) in double distilled water. At first, $50 \mathrm{~mL}$ of $0.024 \mathrm{M} \mathrm{K}_{2} \mathrm{HPO}_{4} \cdot 3 \mathrm{H}_{2} \mathrm{O}$ solution containing various concentrations $(0.0012 \mathrm{M}-0.24 \mathrm{M})$ of CTAB was prepared under constant stirring at $50{ }^{\circ} \mathrm{C}$ for $30 \mathrm{~min}$ to ensure cooperative interaction to accomplish self-assembling process. This was followed by the gradual addition of $50 \mathrm{~mL}$ of calcium nitrate solution $(0.04 \mathrm{M})$ and the resultant mixture was mixed thoroughly with magnetic stirring. $\mathrm{pH}$ of the solution was then adjusted to 9 by adding $\mathrm{NH}_{3}$. The white suspension thus obtained was put in a teflon vessel, sealed tightly and heated by microwave irradiation $(2.45 \mathrm{GHz}, 900 \mathrm{~W}, \mathrm{LG}$, India) for $30 \mathrm{~min}$. The white precipitate formed was gently washed with double distilled water to remove the residual CTAB and then dried at $80{ }^{\circ} \mathrm{C}$ for $12 \mathrm{~h}$. The obtained powders were then calcined in a muffle furnace at $900{ }^{\circ} \mathrm{C}$ for $2 \mathrm{~h}$. The above experiment was repeated for three times in order to get reproducibility of the results.

The as-synthesized nanohydroxyapatite particles were characterized by Fourier transform infrared spectroscopic (FT-IR) technique (Nicolet 380 FT-IR spectrophotometer) over the wavenumber ranging from 4000 to $400 \mathrm{~cm}^{-1}$ with 32 number of scans and a resolution of $4 \mathrm{~cm}^{-1}$. For this, a small amount of HAp powder $(\sim 2 \mathrm{mg})$ was blended with $\mathrm{KBr}$ and then pressed into discs and FT-IR spectrum was recorded.

Phase composition and crystallinity of the calcined HAp particles were determined by X-ray diffraction (XRD, Bruker D-8 Advance, Germany) with $\mathrm{CuK} \alpha$ radiation, $\lambda=$ $1.5406 \AA$, generated at $35 \mathrm{kV}$ and $25 \mathrm{~mA}$. Data were collected over $2 \theta$ range of $20-60^{\circ}$ with a step size of $0.010^{\circ}$ and a count time of $0.2 \mathrm{~s}$.

The fraction of crystallinity, $X_{\mathrm{c}}$, of the nanohydroxyapatite powders was determined (Degirmenbasi et al 2006; Gopi et al 2010a, b, 2012) from the following equation:

$$
X_{\mathrm{c}}=(0 \cdot 24 / \beta)^{3},
$$

where $\beta$ is the full width at half maximum (FWHM) for the diffraction peak under consideration.

Morphology and microstructure of the as-synthesized powders were characterized by scanning electron microscope (SEM, JEOL, Japan) and transmission electron microscopic (TEM) images were obtained from Philips CM12 transmission electron microscope operating at $120 \mathrm{kV}$.

\section{Results and discussion}

Figure 1(a-c) shows FT-IR spectra of the nanohydroxyapatite powders synthesized at various concentrations of CTAB and calcined at $900{ }^{\circ} \mathrm{C}$ for $2 \mathrm{~h}$. It is observed that $v_{1}$ vibration mode of the phosphate group is found around $960 \mathrm{~cm}^{-1}$ and $v_{2}$ mode of the phosphate group appears at $472 \mathrm{~cm}^{-1}$. The peaks around 1030 and $1080 \mathrm{~cm}^{-1}$ are due to $v_{3}$ mode of the phosphate group while the peaks at $560-606 \mathrm{~cm}^{-1}$ correspond to $v_{4}$ mode of the phosphate group. The broad band around $3420 \mathrm{~cm}^{-1}$ is due to the adsorbed lattice water and a peak at $1636-1641 \mathrm{~cm}^{-1}$ is due 


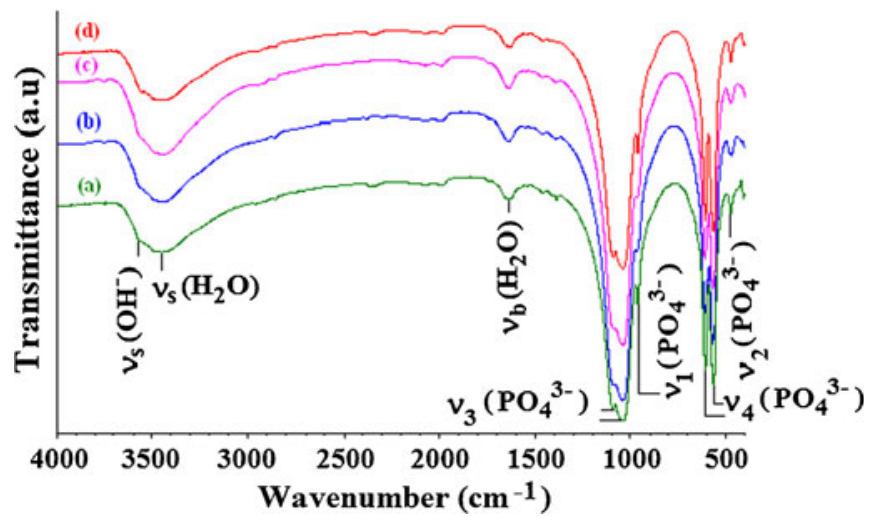

Figure 1. FT-IR spectra of HAp nanoparticles synthesized in presence of different CTAB concentrations: (a) 0.0012 M, (b) $0.012 \mathrm{M},(\mathbf{c}) 0.024 \mathrm{M}$ and (d) $0.24 \mathrm{M}$.

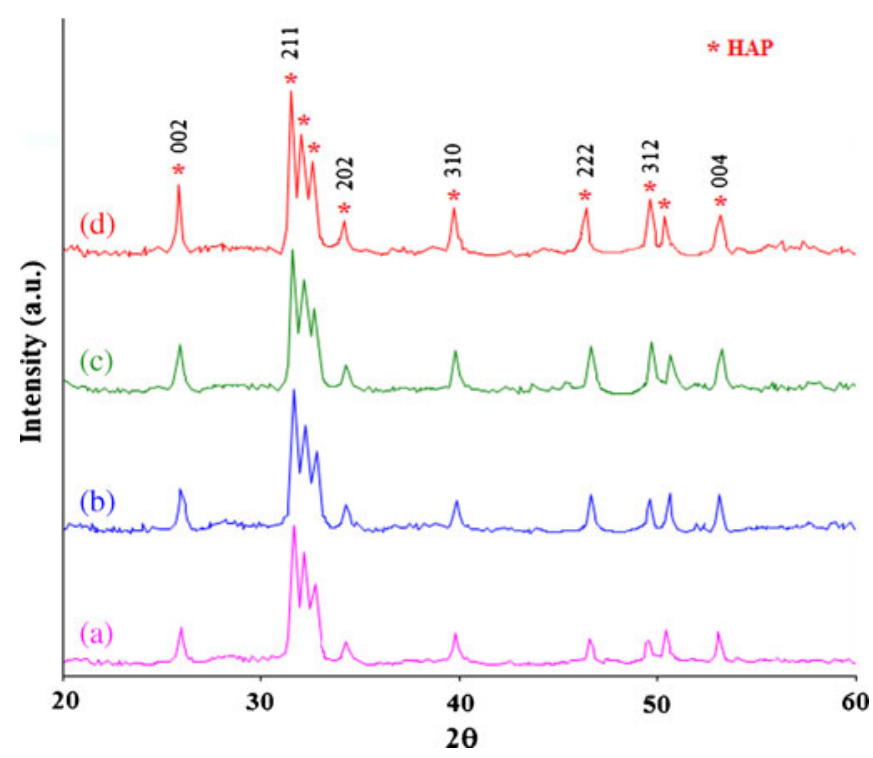

Figure 2. XRD patterns of uncalcined HAp nanoparticles synthesized in presence of different CTAB concentrations: (a) $0.0012 \mathrm{M}$, (b) $0.012 \mathrm{M}$, (c) $0.024 \mathrm{M}$ and (d) $0.24 \mathrm{M}$.

to $\mathrm{O}-\mathrm{H}$ bending mode. Furthermore, $\mathrm{OH}$ stretching is found around $3561 \mathrm{~cm}^{-1}$. It could also be observed that no peaks corresponding to CTAB could be detected in the spectrum indicating purity of the samples synthesized. For all the concentrations, the spectra showed well-resolved peaks indicating the formation of pure HAp particles. The spectra showed all the prominent peaks that are attributable to HAp powders as reported already in the literature (Rehman and Bonfield 1995 ) and the results observed were also consistent with our previous studies (Gopi et al 2008, 2009, 2010a, b, 2012).

Figure 2 shows XRD patterns of uncalcined HAp nanoparticles synthesized at various concentrations of CTAB. In all CTAB concentrations, the characteristic peaks appearing in the XRD pattern shown in figure 2(a-d) are attributed to HAp reflections and no characteristic peaks of impurities are
Table 1. Crystallinity of uncalcined HAp synthesized from various concentrations of CTAB.

\begin{tabular}{|c|c|c|c|}
\hline $\begin{array}{l}\text { Sample } \\
\text { conditions }\end{array}$ & Plane & $\begin{array}{l}\text { Line width } \\
\text { (FWHM) }\end{array}$ & $\begin{array}{c}\text { Fraction of } \\
\text { crystallinity }\left(X_{\mathrm{c}}\right)\end{array}$ \\
\hline $0 \cdot 0012 \mathrm{M}$ & $\left(\begin{array}{lll}0 & 0 & 2\end{array}\right)$ & $0 \cdot 222$ & $1 \cdot 26$ \\
\hline $0.012 \mathrm{M}$ & $\left(\begin{array}{lll}0 & 0 & 2\end{array}\right)$ & $0 \cdot 219$ & $1 \cdot 32$ \\
\hline $0.024 \mathrm{M}$ & $\left(\begin{array}{lll}0 & 0 & 2\end{array}\right)$ & $0 \cdot 215$ & 1.39 \\
\hline $0.24 \mathrm{M}$ & $\left(\begin{array}{lll}0 & 0 & 2\end{array}\right)$ & $0 \cdot 208$ & 1.53 \\
\hline
\end{tabular}

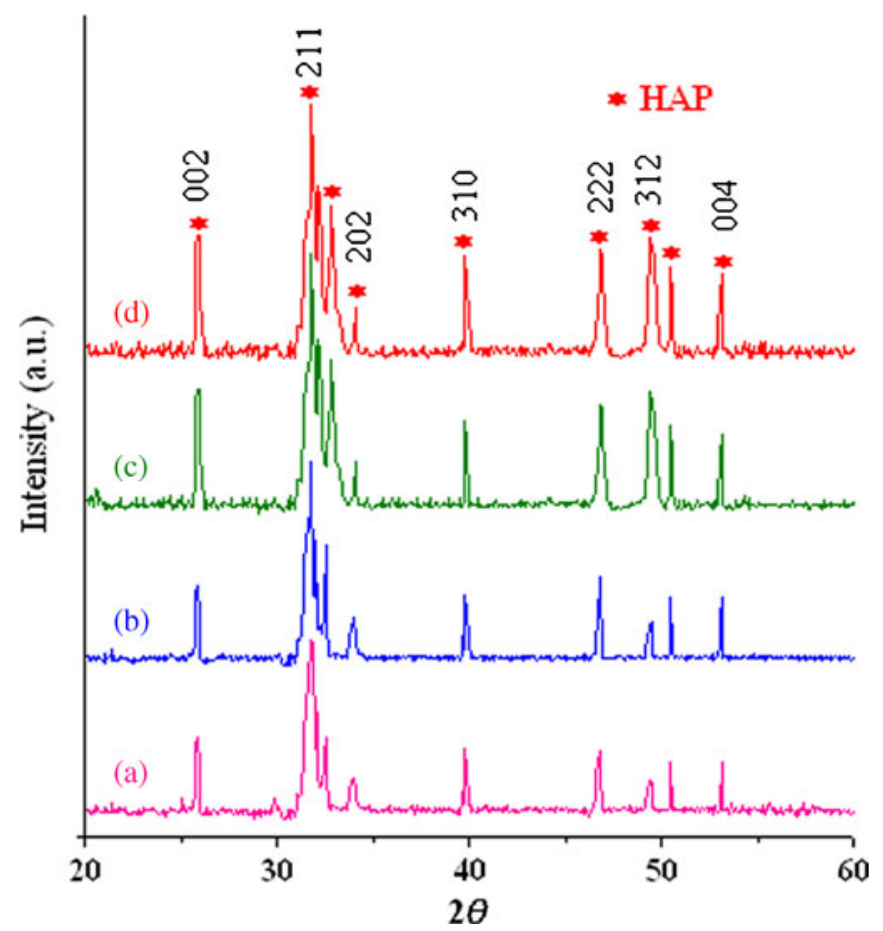

Figure 3. XRD patterns of calcined HAp nanoparticles synthesized in presence of different CTAB concentrations: (a) $0.0012 \mathrm{M}$, (b) $0.012 \mathrm{M}$, (c) $0.024 \mathrm{M}$ and (d) $0.24 \mathrm{M}$.

observed which are well consistent with ICDD card no. 090432 . There are no differences except the intensity observed in XRD patterns between the samples synthesized at different concentrations of CTAB. From figure $2(a-d)$, it is evident that the intensity of diffraction peaks increase with an increase in CTAB concentration which strongly suggest the increased crystallinity of the as-synthesized HAp sample, i.e. there is also a sign of directional growth in XRD patterns. In a standard HAp pattern, the intensity of diffracted X-rays corresponding to (211) and (002) planes are assumed to be 100 and 40 units, respectively thus the ratio $I(211) / I(002)$ is equal to 2.5. In the case of HAp synthesized with $0.0012 \mathrm{M}$ concentration of CTAB, intensity of the diffracted peaks corresponding to planes (002) and (211) are measured to be 20.4 and 64 units, respectively and the ratio $I(211) / I(002)$ is 3.1. Whereas, for the HAp synthesized with different CTAB concentrations such as $0.012,0.024$ and $0.24 \mathrm{M}$, the ratio of $I(211) / I(002)$ are found to be $3.20(69 / 21.5), 3 \cdot 25$ $(71.56 / 22.01)$ and $3.38(75.52 / 22 \cdot 3)$, respectively. Increase 
in the crystallinity for the uncalcined HAp samples synthesized at various $\mathrm{CTAB}$ concentrations is further substantiated by the calculated crystallinity values from XRD results. The diffraction peak at $\left(\begin{array}{lll}0 & 0 & 2\end{array}\right)$ plane was chosen for the calculation of crystallinity since, it is sharper and isolated from others and the results are presented in table 1.

XRD patterns obtained for HAp powders using all studied concentrations of CTAB followed by calcination at $900{ }^{\circ} \mathrm{C}$ for $2 \mathrm{~h}$ are presented in figure 3 . All the peaks detected are attributed to HAp. An increase in peak's intensity could also been observed upon increasing $\mathrm{CTAB}$ concentration owing to a concomitant increase in crystallinity. In particular, the diffraction peak at $25 \cdot 875^{\circ}$ corresponding to the plane $\left(\begin{array}{lll}0 & 0 & 2\end{array}\right)$ are sharp and their relative intensity are far greater than the standard value and are found to be $41 \cdot 26,42 \cdot 18,46 \cdot 38$ and 48.52 , for $0.0012,0.012,0.024$ and $0.24 \mathrm{M} \mathrm{CTAB}$ concentrations, respectively. Therefore, the corresponding ratio of $I(211) / I(002)$ is $1.58(65 \cdot 23 / 41 \cdot 26), 1.62(68 \cdot 36 / 42 \cdot 18)$, $1.94(90 \cdot 102 / 46 \cdot 38)$ and $1.86(90 \cdot 38 / 48.52)$, respectively. This finding strongly reveals the increased crystallinity of the as-synthesized sample and the longitudinal direction of HAp

Table 2. Crystallinity of calcined HAp synthesized from various concentrations of CTAB.

\begin{tabular}{|c|c|c|c|}
\hline $\begin{array}{l}\text { Sample } \\
\text { conditions }\end{array}$ & Plane & $\begin{array}{l}\text { Line width } \\
\text { (FWHM) }\end{array}$ & $\begin{array}{c}\text { Fraction of } \\
\text { crystallinity }\left(X_{\mathrm{c}}\right)\end{array}$ \\
\hline $0 \cdot 0012 \mathrm{M}$ & $\left(\begin{array}{lll}0 & 0 & 2\end{array}\right)$ & $0 \cdot 105$ & 11.93 \\
\hline $0 \cdot 012 \mathrm{M}$ & $\left(\begin{array}{lll}0 & 0 & 2\end{array}\right)$ & $0 \cdot 101$ & $13 \cdot 41$ \\
\hline $0.024 \mathrm{M}$ & $\left(\begin{array}{lll}0 & 0 & 2\end{array}\right)$ & 0.097 & $15 \cdot 14$ \\
\hline $0 \cdot 24 \mathrm{M}$ & $\left(\begin{array}{lll}0 & 0 & 2\end{array}\right)$ & 0.091 & $18 \cdot 33$ \\
\hline
\end{tabular}
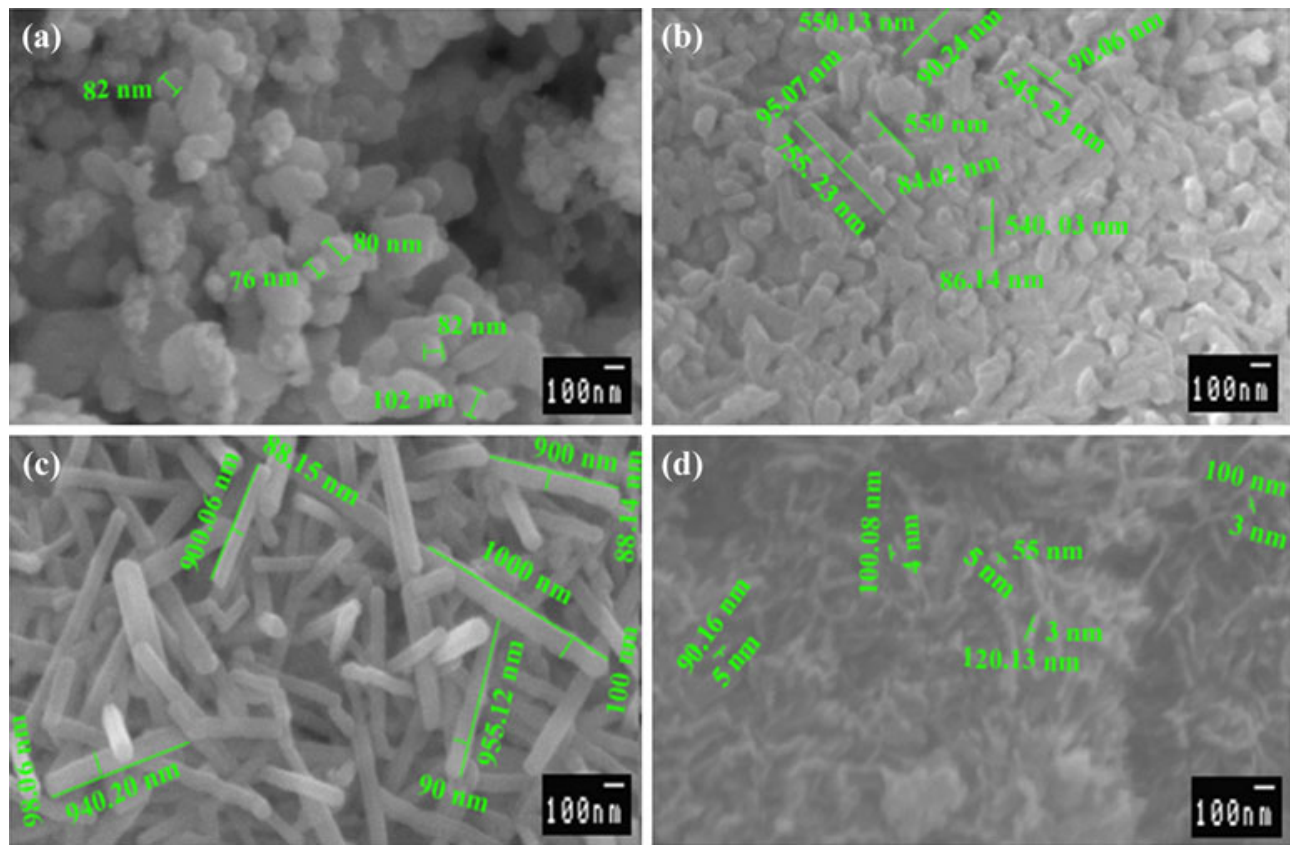

Figure 4. SEM images of HAp nanoparticles synthesized in presence of different CTAB concentrations: (a) 0.0012 M, (b) 0.012 M, (c) 0.024 M and (d) 0.24 M. nanorods as well as nanofibres are in $\left(\begin{array}{lll}0 & 0 & 2\end{array}\right)$ plane, and they are oriented to grow along the $c$-axis more preferentially. Moreover, crystallinity of the HAp increases as the concentration of CTAB increases which is evidenced from the calculated crystallinity values presented in table 2 . This is in conformation with TEM results that will be discussed later. Our XRD results are in excellent agreement with the standard diffraction data (ICDD file no. 09-0432).

The synthesis process at each concentration of CTAB was repeated for three times in order to check reproducibility of the results. But the morphological images of the obtained nanostructure at various concentrations of CTAB are presented only for one trial which is shown in figure 4 . The shape, size, aspect ratio and standard deviation of the obtained nanostructures are discussed in detail as follows. When CTAB concentration was maintained at $0.0012 \mathrm{M}$, which is much closer to the critical micelle concentration (CMC) (Delsannti et al 1993), the particles were almost spherical in shape (figure 4(a)). This could be explained in view of the fact that, at $\mathrm{CMC}, \mathrm{CTAB}$ in aqueous solution forms spherical micelles and, therefore, the obtained particles were essentially spherical and size of the particles ranges from $69-102 \mathrm{~nm}$ with a mean size of $83.4 \mathrm{~nm}$ and 9.066 is its standard deviation. On increasing the concentration of CTAB, shape of the micelle was transformed into an elongated one which is supported from the formation of slightly elongated nanorod structures as seen in figure 4(b). But its formation is not uniform throughout and size of the nanorods ranging from 535.67-768.08 nm in length and $80.16-95.07 \mathrm{~nm}$ in diameter with a standard deviation of 0.773 and the mean length, diameter and aspect ratios being $589.65,88.54$ and $6.7 \mathrm{~nm}$, respectively. 
Whereas, uniform HAp nanorods (figure 4(c)) with length and width ranging from $884 \cdot 14-1000$ and $80 \cdot 12-100 \mathrm{~nm}$ and a standard deviation of 0.456 could be achieved for a CTAB concentration of $0.024 \mathrm{M}$. The nanorods obtained are much thinner, longer with uniform size distribution and are random in orientation. From this micrograph, it is clearly evident that the mean average diameter, mean length and mean aspect ratio were found to be $91.46 \mathrm{~nm}, 936.43 \mathrm{~nm}$ and $10 \cdot 2$, respectively. On further increasing the concentration of CTAB to $0.24 \mathrm{M}$, shape of the HAp nanorods is transformed to nanofibres (figure 4(d)) owing to the change in fibre-like micellar structure of CTAB.
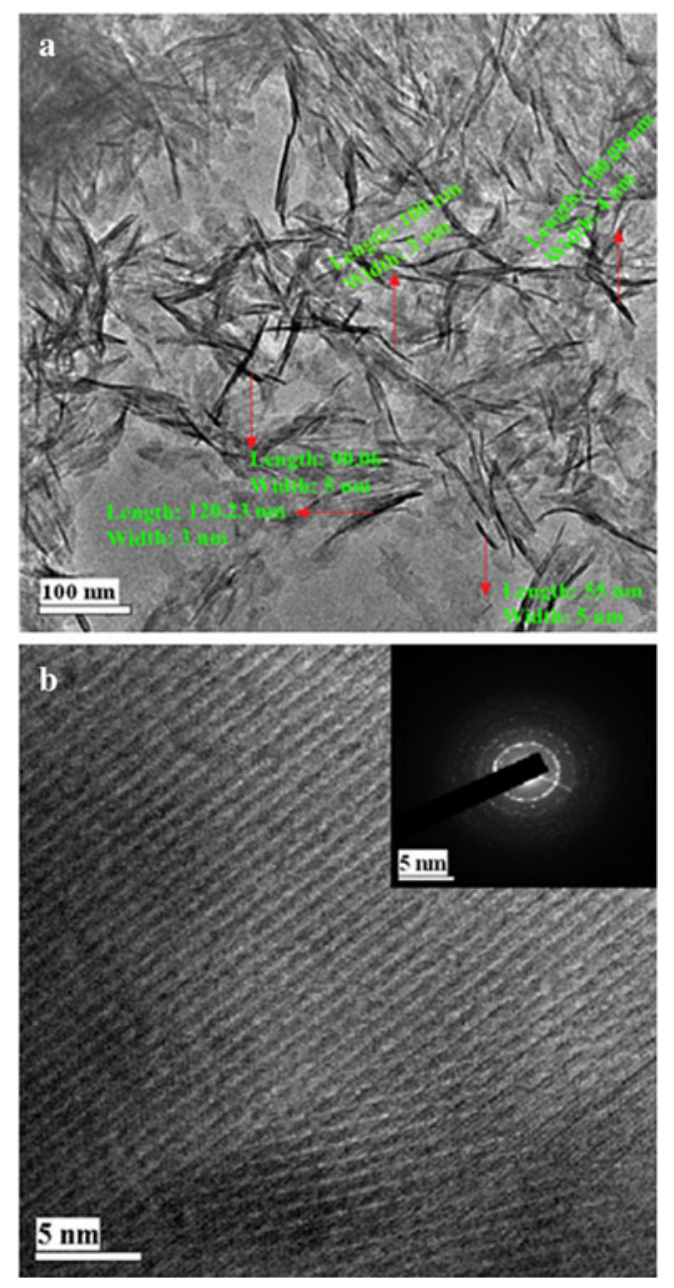

Figure 5. (a) TEM images for HAp nanofibres and (b) HRTEM image of a single nanofibre (inset: electron diffraction pattern).
TEM images of the HAp nanofibres obtained from 0.24 M concentration of CTAB is shown in figure 5. As seen from the image, it was estimated that length and diameter of the nanofibres ranged from 45.38-120.13 nm and 3-5 nm (figure 5(a)) with a standard deviation of 9.261. HAp nanofibres were straight and long with mean length and diameter of 90.78 and $3.93 \mathrm{~nm}$, respectively, resulting in a very large aspect ratio of around 24.6 which were well consistent with the previously reported results (Liu et al 2002). The high resolution transmission electron microscopic (HRTEM) image shows uniform lattice array of atoms (figure 5(b)). Moreover, the resultant nanofibres showed good crystallinity which is evident from the obtained electron diffraction (figure 5(b) inset) pattern. The above morphological results and the mean, standard deviation of the reproduced results reveal that the size and morphology of the as-synthesized HAp particles can be effectively controlled by tuning the concentration of CTAB as an only surfactant used in this synthesis under microwave irradiation method. Liu et al (2005) emphasized that the presence of CTAB, PEG 400 and ethanoic acid are crucial for the formation of HAp nanorods. But in our system, there is no need to use the other cosurfactants like PEG, TX-100, ethanoic acid, ammonium nitrate and other oil phase systems such as cyclohexane, $n$ pentanol, $n$-butanol, $n$-hexanol to control the microstructure of as-synthesized HAp as reported by other workers previously (Liu et al 2002, 2005; Kalita et al 2007; Salarian et al 2009). Further, there is no need to use high reaction temperature ranging from 90 to $150{ }^{\circ} \mathrm{C}$ for the synthesis of pure HAp nanorods and nanofibres (Yan et al 2001; Wang et al 2006; Salarian et al 2009). Moreover, in our study, we used microwave irradiation as an assistant technology which yields phase pure HAp nanostructures rapidly as evident from XRD results (figures 2 and 3) as discussed before and this method consumes less time compared to other conventional methods. Besides, it is interesting to note that the aspect ratio and crystallinity of the as-synthesized HAp nanostructures increase while changing the morphology from rod-like to fibre-like structure (table 2).

The growth modification achieved through CTAB addition could be explained as follows: at the critical micelle concentration $(\mathrm{CMC})(0 \cdot 001 \mathrm{M})$, the surfactant CTAB tends to form spherical-shaped micelle and resulting in the ingrowth of spherical-shaped nano-HAP particles (Lin et al 2007). In aqueous solutions, CTAB ionizes thoroughly and forms cations with tetrahedral structures similar to phosphate anions. Subsequent attachment of CTAB cations with phosphate anions results in spherical-shaped HAp owing to the

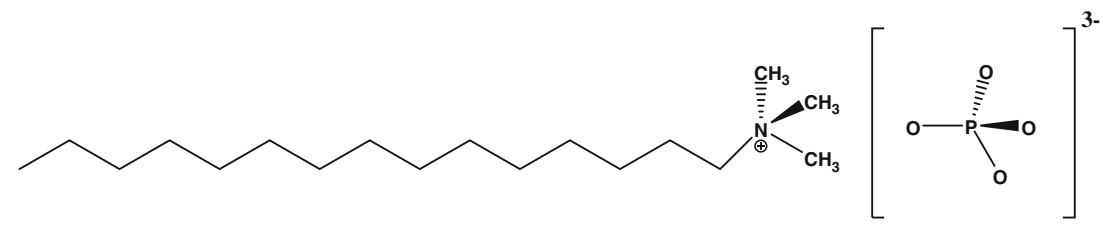

Figure 6. Schematic sketch showing charge to structure complementarity of surfactant. 

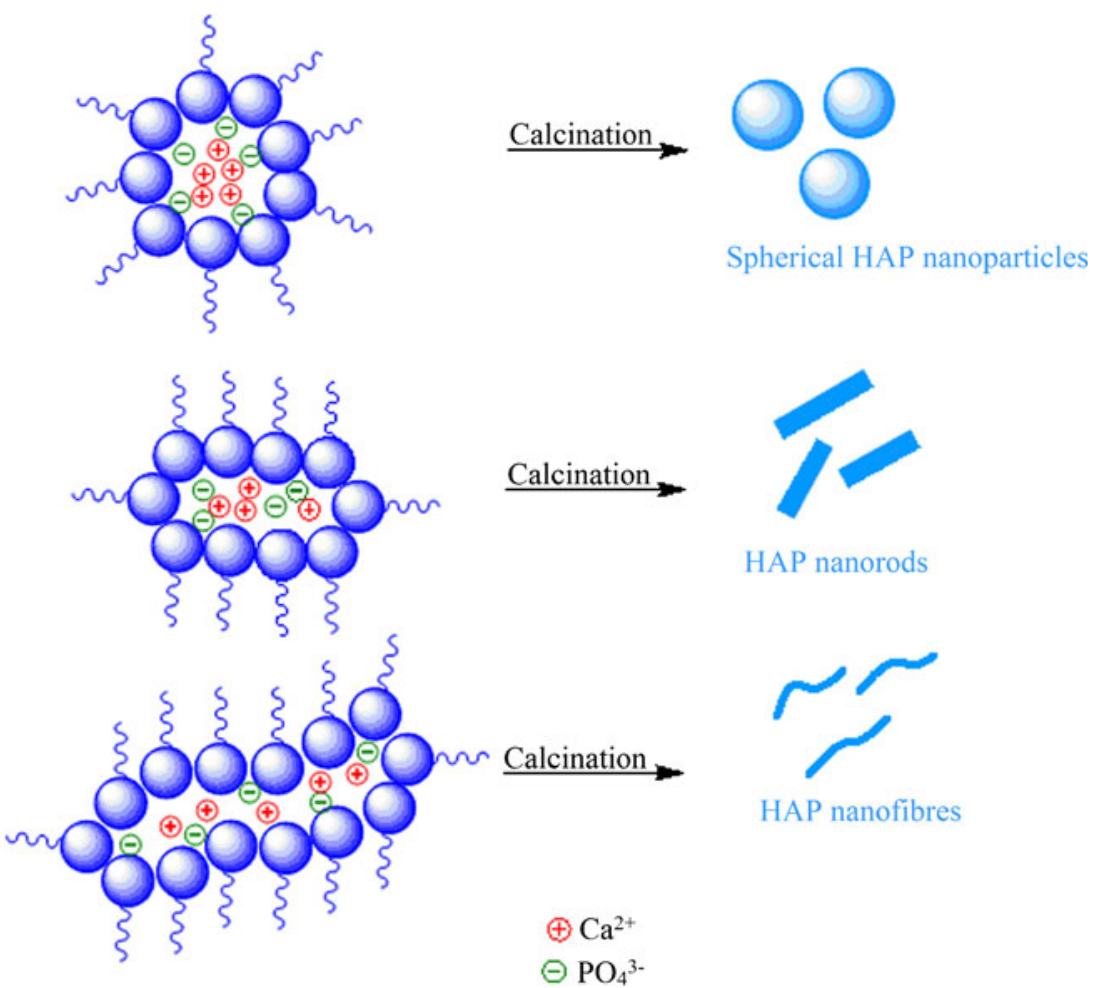

Figure 7. Mechanism of formation of HAp nanospheres, nanorods and nanofibres through different CTAB micelle structures.

appropriate charge and structure complimentarity as shown in figure 6 (Shih et al 2004; Sun et al 2007).

When the concentration of the surfactant is maintained above its CMC, CTAB tends to form rod-like micelles (Wang et al 2006). The micelles act as nucleating points for the growth of HAp crystals and during the reaction, CTABHAp complexes are produced and they coalesce to control the morphology and size of obtained HAp. Since the crystallization process is under critical control of CTAB concentration, the resulting HAp consisted invariably of nanorods with uniform morphology and controllable size.

On further increasing the concentration of CTAB above its CMC, size of the micelles increased eventually resulting in long, flexible worm-like micelles (Han et al 2003) and hence, the ingrowth of HAp nanofibres are facilitated and these structures could be obtained at a much higher concentration $(0.24 \mathrm{M})$. The growth of micelles leads to an elongated structure that can occur by two mechanisms (Salarian et al 2009). In the first, there may be an internal driving force which causes the formation of large aggregates with a different geometry. Whereas, in the other mechanism, the micellar growth was induced by the repulsions of the intermicelles when the micelles come in direct or close contact which allows a better packing of the micelle and this phenomenon occurred at high concentrations of CTAB. Hence, the surfactant (CTAB) plays the role of a template for the overall synthesis of nanohydroxyapatite spheres, rods and fibres (figure 7). Since bone is a composite of natural fibres like collagen, these fibrous-like nanobiomaterials could enhance bone formation and tissue regeneration when employed in biomedical applications.

\section{Conclusions}

Nano-sized HAp particles with different growth modifications were successfully achieved through a rapid hydrothermal technique using CTAB as an only surfactant. The surfactant acted as a template for the overall synthesis of fine nano-sized spheres, rods and fibres and the assistance of microwave irradiation resulted in rapid formation of nanohydroxyapatite. FT-IR and XRD results prove the formation of pure hydroxyapatite particles and complement each other in confirming quality of the product. SEM results have depicted the formation of spherical, rod-like and fibre-shaped HAp particles. The growth of HAp nanofibres is evident from TEM evaluations. Such nanomaterials with designable structures could be potential candidates for coating implant materials intended for biomedical applications.

\section{Acknowledgements}

One of the authors (DG) acknowldges major financial support from the Indian Council of Medical Research (ICMR, IRIS ID no. 2010-08660, Ref. no. 5/20/11(Bio)/10-NCD-I), the Department of Science and Technology (DST-SERB, Ref. no. SB/EMEQ-185/2013 and DST-TSD, Ref. no. 
DST/TSG/NTS/2011/73) and the Council of Scientific and Industrial Research (CSIR, Ref. no. 01(2547)/11/EMR-II) New Delhi, in the form of major research projects. Another author (JI) wishes to thank the Council of Scientific and Industrial Research (CSIR), New Delhi, for the award of a Senior Research Fellowship (CSIR-SRF).

\section{References}

Anee Kuriakose T, Narayana Kalkura S, Palanichamy M, Arivuoli D, Karsten Dierks G, Bocelli C and Betzel 2004 J. Cryst. Growth 263517

Arami H, Mohajerani M and Mazloumi M 2009 J. Alloys Compd. 469391

Bezzi G, Celotti G, Landi E, La Torretta T M G, Sopyan I and Tampieri A 2003 Mater. Chem. Phys. 78816

Degirmenbasi N, Kalyon D M and Birinci E 2006 Coll. Surf. B: Biointerf. 4842

Delsannti M, Moussaid A and Munch J P 1993 J. Coll. Interf. Sci. 157285

Gopi D, Govindaraju K M, Prakash V C A, Kavitha L and Rajendran N 2008 Spectrochim. Acta Part A 701243

Gopi D, Indira J, Collins Arun Prakash V and Kavitha L 2009 Spectrochim. Acta Part A $\mathbf{7 4} 282$

Gopi D, Indira J, Kavitha L, Kannan S and Ferreira J M F 2010a Spectrochim. Acta: Mol. Biomol. Spectrosc. A 77545

Gopi D, Bhalaji P R, Prakash V C A, Kavitha L, Ramasamy A K and Ferreira J M F 2010b Curr. Appl. Phys. 11590

Gopi D, Indira J, Kavitha L, Sekar M and Kamachi Mudali U 2012 Spectrochim. Acta: Mol. Biomol. Spectrosc. A 93131

Han S H, Hou W G and Dang W X 2003 Mater. Lett. 574520

Hattori H and Iwadate Y 1990 J. Am. Ceram. Soc. 731803

Hench L L 1991 J. Am. Ceram. Soc. 741487

Jiang Y, Zhu Y J and Xu Z L 2006 Mater. Lett. 602294

Kalita S J, Bhardwaj A and Bhatt H A 2007 Mater. Sci. Eng. C 27 441
Kim W, Zhang Q and Saito F 2000 J. Mater. Sci. 355401

Laurencin C T, Ambrosio A M A and Borden M D 1999 Ann. Rev. Biomed. Eng. 119

Lerner E, Sarig S and Azoury R 1991 J. Mater. Sci. Mater. Med. 2 138

Lim G K, Wang J and Gan L M 1996 Mater. Lett. 28431

Lin K, Chang J and Cheng R 2007 Mater. Lett. 611683

Liu Y, Wang W, Zhan Y, Zheng C and Wang G 2002 Mater. Lett. 56 496

Liu J, Li K, Wang H, Zhu M, Xu H and Yan H 2005 Nanotechnology 1682

Macipe A L, Morales J G and Clemente R R 1998 Adv. Mater. 1049

Murray M G, Wang J, Ponton C B and Marquis P M 1995 J. Mater. Sci. 303061

Rambo C R, Muller F A, Muller L, Sieber H, Hofmann I and Greil P 2006 Mater. Sci. Eng. C 2692

Rameshbabu N, Rao K P and Kumar T S S 2005 J. Mater. Sci. 40 6319

Rehman I and Bonfield W 1995 Bioceramics 8163

Remant Bahadur K C, Kim C K, Khil M S, Kim H Y and Kim I S 2008 Mater. Sci. Eng. C $\mathbf{2 8} 70$

Sarda S, Heughebaert M and Lebugle A 1999 Chem. Mater. 11 2722

Sarig S and Kahana F 2002 J. Cryst. Growth 237-239 55

Shih W J, Chen Y F and Wang M C 2004 J. Cryst. Growth 270211

Salarian M, Solati-Hashjin M, Sara Shafiei S, Goudarzi A, Solarian R and Nemati A 2009 Mater. Sci. Poland 27961

Suchanek W and Yoshimura M 1998 J. Mater. Res. 1394

Sun Y, Guo G, Wang Z and Guo H 2006 Ceram. Inter. 32951

Sun Y, Guo G and Tao D 2007 J. Phys. Chem. Solids 68373

Walsh D and Mann S 1996 Chem. Mater. 81944

Wang Y, Zhang S and Wei K 2006 Mater. Lett. 601484

Yan L, Li Y, Deng Z X, Zhuang J and Sun X 2001 Inter. J. Inorg. Mater. 3633

Yang H, Su X and Tang A 2007 Mater. Res. Bull. 421357

Yeong B, Junmin X and Wang J 2001 J. Am. Ceram. Soc. 84465

Yeong K C B, Wang J and Ng S C 2001 Biomaterials 222705 